\title{
PERBAIKAN SISTEM PERAWATAN MESIN PADA PT XYZ
}

\author{
Tiara Rahmania', A. Rahim Matondang ${ }^{2}$, Nazaruddin $^{3}$ \\ Departemen Teknik Industri, Fakultas Teknik, Universitas Sumatera Utara \\ Jl. Almamater Kampus USU, Medan 20155 \\ Email : yayarahmania@gmail.com
}

\begin{abstract}
Abstrak.PT XYZ merupakan perusahaan yang bergerak dalam industri pakan ternak. Proses produksi pada perusahaan ini sering mengalami kendala seperti adanya kerusakan mesin. Hal ini mengakibatkan terjadinya downtime dengan rata-rata per bulan yang terjadi tahun 2014 sampai Oktober 2015 sebesar 11,21\% atau 43,05 jam. Perbaikan sistem perawatan mesin dapat dilakukan untuk mengurangi downtime tersebut. Sistem perawatan (maintenance) yang berjalan pada perusahaan ini menerapkan metode corrective maintenance dan preventive maintenance. Sistem perawatan usulan yang diberikan yaitu jadwal penggantian spare part berdasarkan perhitungan Total Minimum Downtime. Interval penggantian yang diusulkan untuk komponen kritis Hammer Mill yaitu Beater PCD 80mm (5x50x150xØ17mm) 288 jam, Screen 695x1120x3DxØ3mm 320 jam, Screen 695x1120x3DxØ8mm 416 jam dan Hammer Bolt 7002D 480 jam. Selain itu, untuk mendukung sistem perawatan yang diusulkan maka diperlukan persediaan spare part yang optimal. Dengan menerapkan sistem perawatan usulan terjadi penurunan downtime pada perusahaan yang cukup signifikan sebesar $29,97 \%$ dan peningkatan nilai keandalan sebesar $37,05 \%$.
\end{abstract}

Kata Kunci: Perawatan, Downtime, TMD dan Persediaan Spare Part

\begin{abstract}
PT XYZ is a company which operates in cattle fodder industry. Its production process often faces obstacles and one of them is machine breakdown which causes the incidence of downtime of $11,21 \%$ or 43,05 hours each month from 2014 until October, 2015. The improvement of machine maintenance can be done to decrease this downtime. Maintenance system in this company applies corrective maintenance and preventive maintenance. The proposed maintenance system is the schedule for changing spare parts according to the calculation of Total Minimum Downtime. The proposed changing interval for Hammer Mill critical component was Beater PCD $80 \mathrm{~mm}(5 \times 50 x 150 x \emptyset 17 \mathrm{~mm}) 288$ hours, Screen 695x1120x3DxØ3mm 320 hours, Screen 695x1120x3DxØ8mm) 416 hours, and Hammer Bolt 700-2D 480 hours. Besides that, spare parts should be optimally available in order to support the proposed maintenance system. The implementation of the proposed maintenance system had significant decrease in downtime of $29,97 \%$ and the increase in reliability value of $37,05 \%$.
\end{abstract}

Keywords: Maintenance, Downtime, TMD and Spare Part Inventory

\footnotetext{
${ }^{1}$ Mahasiswa Magister Teknik Industri Fakultas Teknik Universitas Sumatera Utara

${ }^{2}$ Dosen Departemen Teknik Industri Fakultas Teknik Universitas Sumatera Utara

${ }^{3}$ Dosen Departemen Teknik Industri Fakultas Teknik Universitas Sumatera Utara
} 


\section{PENDAHULUAN}

Semakin pesatnya persaingan antar perusahaan manufaktur mengharuskan setiap perusahaan melakukan perbaikan secara berkelanjutan (continuous) agar proses produksi berjalan lancar. Mesin produksi merupakan salah satu faktor utama untuk menjaga agar proses produksi di perusahaan berjalan lancar. Tetapi tidak jarang terganggunya proses produksi disebabkan adanya masalah dalam mesin produksi tersebut misalnya karena kerusakan mesin pada saat proses produksi sedang berlangsung, hal ini mengakibatkan terjadinya downtime dan tentu akan menimbulkan kerugian bagi perusahaan.

Proses produksi pada perusahaan ini sering mengalami kendala seperti terganggunya proses produksi akibat adanya kerusakan pada mesin produksi. Masalah tersebut mengakibatkan downtime pada perusahaan. Downtime yang terjadi di PT XYZ selama 2014 sampai Oktober 2015 rata-rata per bulan sebesar $11,21 \%$ atau 43,05 jam. Untuk mengurangi downtime tersebut dapat dilakukan dengan maintenance effectiveness (Muchiri, 2008)

Sistem perawatan yang dilakukan oleh PT XYZ adalah corrective maintenance dan preventive maintenance. Ketika terjadi kerusakan, pihak perusahaan hanya mengganti komponen yang rusak tanpa memperhatikan keandalan mesin. Selain itu, tidak terdapat jadwal penggantian komponen atau spare part mesin.

Menurut Nepal dan Park (2004), downtime disebabkan oleh tidak tersedianya peralatan dan kerusakan peralatan adalah factor umum terbesar yang mempunyai pengaruh kuat terhadap produktivitas peralatan dan performansi perusahaan. Dari penelitian yang dilakukan oleh Nepal dan Park (2004), terdapat beberapa faktor yang mengakibatkan tingginya downtime yaitu faktor manusia, strategi yang dijalankan perusahaan, proyek, lokasi, peralatan atau mesin dan tindakan manajemen.

Selain itu, kegiatan perawatan mesin sangat dipengaruhi oleh ketersediaan spare part. Perlu pengelolaan spare part yang tepat agar dapat mendukung kegiatan perawatan mesin di perusahaan.

\section{METODE PENELITIAN}

Metode penelitian merupakan tahapan-tahapan, petunjuk pelaksanaan atau petunjuk teknis dalam melakukan pencarian masalah, penentuan solusi dan mencari solusi dari masalah penelitian.

\subsection{Variabel Penelitian}

Pada penelitian ini terdapat dua variabel, yaitu sebagai berikut:

1. Variabel dependen.

Variabel dependen merupakan variabel yang nilai atau valuenya dipengaruhi atau ditentukan oleh nilai variabel lain. Variabel dependen dalam penelitian ini adalah downtime tinggi.

2. Variabel independen.

Variabel independen merupakan variabel yang mempengaruhi variabel dependen baik secara positif maupun secara negatif. Variabel independen dalam penelitian ini adalah manusia, strategi perusahaan, proyek, lokasi, peralatan atau mesin yang digunakan dan tindakan manajemen.

Penelitian dapat terlaksana secara sistematis dan menjadi lebih mudah jika tersedia kerangka konseptual penelitian yang akan dilakukan. Kerangka konseptual dalam penelitian ini dapat dilihat seperti pada Gambar 1 di bawah ini :

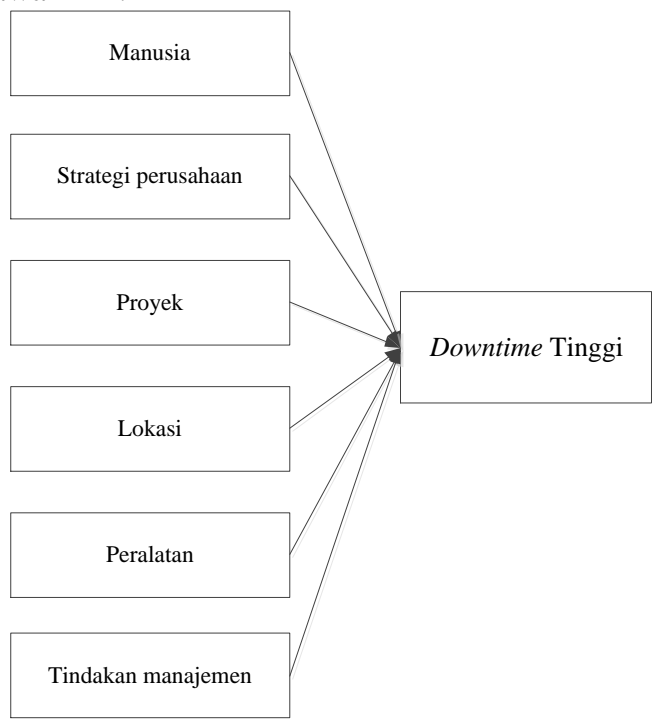

Gambar 1. Kerangka Konseptual Penelitian

\subsection{Metode Pengumpulan Data}

Data yang dikumpulkan dalam penelitian ini terdiri atas dua jenis yaitu:

1. Data primer merupakan data yang diperoleh langsung dari sumbernya dengan cara menyebarkan kuesioner, melakukan pengamatan langsung dan wawancara. Data primer dalam penelitian ini adalah hasil kuesioner untuk mengetahui faktor-faktor yang mengakibatkan tingginya downtime dan sistem perawatan mesin aktual yang dilakukan oleh perusahaan.

2. Data sekunder adalah data yang sudah tersedia oleh pihak lain sehingga tidak perlu lagi dikumpulkan secara langsung dari sumbernya oleh peneliti. Data sekunder yang diperlukan dalam penelitian ini berupa data mesin yang digunakan, data kerusakan mesin, data pemakaian spare part, harga pembelian masing-masing spare part dan biaya-biaya 
yang diperlukan dalam pengendalian persediaan seperti biaya pemesanan, biaya penyimpanan dan biaya kekurangan persediaan.

\subsection{Metode Pengolahan Data}

Langkah-langkah pengolahan data yang dilakukan dalam penelitian ini adalah sebagai berikut:

1. Identifikasi sistem perawatan sekarang (existing).

2. Uji validitas dan reliabilitas.

3. Analisis korelasi.

4. Pemilihan mesin kritis dengan menggunakan diagram pareto.

5. Pemilihan komponen atau spare part dari mesin kritis yang terpilih menggunakan analisis $\mathrm{ABC}$.

6. Penentuan pola distribusi data kerusakan spare part yang terpilih menggunakan software Easy Fit Professional 5.6.

7. Menghitung nilai mean time to failure (MTTF).

8. Menentukan jadwal penggantian komponen (spare part) mesin kritis berdasarkan total minimum downtime (TMD).

9. Menghitung jumlah pemesanan spare part atau komponen mesin yang optimal, reorder point dan safety stock.

\section{HASIL DAN PEMBAHASAN}

\subsection{Perancangan Perawatan Mesin}

Sebelum melakukan perancangan perawatan mesin, terlebih dahulu dilakukan pengolahan data dari kuesioner yang telah disebarkan di PT XYZ. Hasil kuesioner tersebut dilakukan uji validitas, uji reliabilitas dan analisis korelasi. Dari hasil perhitungan analisis korelasi didapatkan bahwa faktor kedua yaitu strategi perusahaan memiliki koefisien korelasi yang tertinggi yaitu sebesar 0,8402 .

Faktor strategi perusahaan terdiri dari beberapa indikator yaitu keputusan penggantian, sistem pengadaan, manajemen inventori dan kebijakan maintenance. Oleh karena itu, penyelesaian permasalahan dalam penelitian ini difokuskan pada perawatan (maintenance) mesin dan pengelolaan persediaan spare part untuk mendukung kegiatan perawatan mesin yang diusulkan.

Pada penelitian ini diusulkan jadwal penggantian spare part mesin berdasarkan total minimum downtime (TMD). Prinsip dasar pendekatan TMD adalah untuk menekan periode kerusakan sampai batas downtime yang paling minimum sehingga tujuan utama kegiatan perawatan mesin dapat tercapai. Jadwal penggantian komponen (spare part) mesin yang diusulkan untuk periode 2016 dapat dilihat pada Tabel 1.

\subsection{PersediaanSpare Part}

Perhitungan persediaan spare part yang diusulkan yaitu dengan menggunakan metode economic order quantity (EOQ) untuk mendapatkan jumlah pemesanan spare part yang ekonomis. Selama ini pada PT XYZ dalam melakukan pemesanan spare part, tidak diketahui besar jumlah pemesanan yang ekonomis. Jumlah pemesanan yang dilakukan hanya berdasarkan perkiraan tanpa adanya dasar perhitungan yang jelas.

Tabel 1. Jadwal Penggantian Spare Part Tahun 2016

\begin{tabular}{|c|c|c|c|c|c|}
\hline \multirow[b]{2}{*}{ Bulan } & \multirow[b]{2}{*}{$\begin{array}{c}\text { Total } \\
\text { Manhours } \\
\text { (Hours) }\end{array}$} & \multicolumn{4}{|c|}{ Jadwal Penggantian (Jam ke-) } \\
\hline & & $\begin{array}{l}\text { Beater PCD } 80 \mathrm{~mm} \\
(5 \times 50 \times 150 \times ø 17 \mathrm{~mm})\end{array}$ & $\begin{array}{c}\text { Screen } \\
695 \times 1120 \times 3 \mathrm{Dx} 03 \mathrm{~mm}\end{array}$ & $\begin{array}{c}\text { Screen } \\
695 \times 1120 \times 3 \mathrm{Dx} 98 \mathrm{~mm}\end{array}$ & $\begin{array}{l}\text { Hammer } \\
\text { Bolt } \\
700-2 \mathrm{D}\end{array}$ \\
\hline Januari & 380 & 288 & 320 & - & - \\
\hline Februani & 320 & 196 & 260 & 36 & 100 \\
\hline Maret & 395 & 164 & 260 & 132 & 260 \\
\hline April & 395 & 57,345 & 185 & 153 & 345 \\
\hline Mei & 400 & 238 & 110 & 174 & - \\
\hline Juni & 390 & 126 & 30,350 & 190 & 30 \\
\hline Juli & 385 & 24,312 & 280 & 216 & 120 \\
\hline Agustus & 390 & 215 & 215 & 247 & 215 \\
\hline September & 395 & 113 & 145 & 273 & 305 \\
\hline Oktober & 405 & 6,294 & 70,390 & 294 & 390 \\
\hline November & 395 & 177 & 305 & 305 & - \\
\hline Desember & 410 & 70,358 & 230 & 326 & 70 \\
\hline
\end{tabular}

Jumlah pemesanan yang ekonomis untuk masingmasing spare part mesin Hammer Mill yang telah diperoleh dari perhitungan menggunakan metode EOQ dapat dilihat padaTabel 2.

Tabel 2. Jumlah Pemesanan Ekonomis

\begin{tabular}{lc}
\hline \multicolumn{1}{c}{ Nama Komponen } & $\begin{array}{c}\mathrm{Q}^{*} \\
\text { (unit) }\end{array}$ \\
\hline $\begin{array}{l}\text { Beater PCD 80mm } \\
(5 \times 50 \times 150 \times \varnothing 17 \mathrm{~mm})\end{array}$ & 1122 \\
Screen 695x1120x3DxØ3mm & 22 \\
Screen 695x1120x3DxØ8mm & 21 \\
Hammer Bolt 700-2D & 23 \\
\hline
\end{tabular}

Selain itu, untuk mengetahui kapan saatnya dilakukan pemesanan spare part kembali maka dilakukan perhitungan reorder point untuk masingmasing spare part kritis. Hasil perhitungan reorder point dapat dilihat padaTabel 3.

Tabel 3. Reorder Point Spare Part Kritis Mesin Hammer Mill

\begin{tabular}{lc}
\hline \multicolumn{1}{c}{ Nama Komponen } & $\begin{array}{c}\text { Reorder Point } \\
\text { (unit) }\end{array}$ \\
\hline Beater PCD 80mm & 177 \\
Screen 695x1120x3DxØ3mm & 5 \\
Screen 695x1120x3DxØ8mm & 7 \\
Hammer Bolt 700-2D & 3 \\
\hline
\end{tabular}


Perhitungan persediaan pengaman (safety stock) juga dilakukan agar dapat diketahui jumlah persediaan spare part yang harus tersedia di gudang penyimpanan. Selama ini perusahaan tidak mengetahui besar jumlah persediaan yang harus tersedia di gudang penyimpanan, sehingga mengakibatkan pada saat terjadinya kerusakan, spare part tidak tersedia dan mengakibatkan terjadinya downtime. Jumlah persediaan pengaman yang diusulkan dapat dilihat padaTabel 4.

Tabel 4. Jumlah Persediaan Pengaman Komponen Kritis

Mesin Hammer Mill

\begin{tabular}{lc}
\hline \multicolumn{1}{c}{ Nama Komponen } & $\begin{array}{c}\text { Safety Stock } \\
\text { (unit) }\end{array}$ \\
\hline Beater PCD 80mm & 75 \\
Screen 695x1120x3DxØ3mm & 1 \\
Screen 695x1120x3DxØ8mm & 1 \\
Hammer Bolt 700-2D & 2 \\
\hline
\end{tabular}

Sistem perawatan yang diusulkan ini dapat menurunkan downtime yang terjadi di PT XYZ dengan rata-rata sebesar $29,97 \%$ dan meningkatkan nilai keandalan (reliability) mesin sebesar 37,05\%.

\section{KESIMPULAN DAN SARAN}

\subsection{Kesimpulan}

Dari penelitian ini dapat disimpulkan bahwa:

1. Faktor-faktor yang mengakibatkan tingginya downtime pada PT XYZ yaitu faktor strategi perusahaan. Faktor tersebut terdiri dari keputusan penggantian spare part mesin, sistem pengadaan spare part, manajemen inventori dan kebijakan maintenance.

2. Sistem perawatan usulan yang diberikan yaitu dengan menetapkan jadwal penggantian spare part berdasarkan perhitungan total minimum downtime (TMD) dan jumlah persediaan sparepart untuk mendukung kegiatan perawatan tersebut.

3. Dengan menerapkan sistem perawatan usulan terjadi penurunan downtime dengan rata-rata penurunan downtime yang cukup signifikan yaitu sebesar $29,97 \%$ dan terjadi peningkatan nilai keandalan (reliability) yang signifikan yaitu rata-rata sebesar 37,05\% dari komponen kritis mesin Hammer Mill.

\subsection{Saran} adalah:

Saran yang dapat diberikan dari penelitian ini

1. Perusahaan sebaiknya mempersiapkan dokumentasi atau record yang baik terhadap kegiatan perawatan yang dilakukan, kerusakan mesin yang terjadi dan jumlah kebutuhan spare part.
2. Perusahaan sebaiknya melakukan sosialisasi kepada operator dan disiplin dalam menjalankan program perawatan tersebut.

3. Penelitian lanjutan dapat dilakukan dengan fokus pada mesin produksi yang lainnya.

\section{DAFTAR PUSTAKA}

1. Abbas, Sachbudi. 2005. Rekayasa Keandalan Produk. Jakarta: Universitas Indonusa Esa Unggul.

2. Assauri, Sofjan. 2008. Manajemen Produksi dan Operasi. Jakarta: Lembaga Penerbit Fakultas Ekonomi Universitas Indonesia.

3. Corder, Antony danKusnul, Hadi. 1996. Teknik Manajemen Pemeliharaan. Jakarta: Erlangga.

4. Higgis, Lindley dan R Keith Mobley. 2002. Maintenance Engineering Handbook. New York: The McGraw-Hill Company.

5. Sinulingga, Sukaria. 2014. Metodologi Penelitian. Edisi III. Medan: USU Press.

6. Sugiyono. 2012. Metode Penelitian Kuantitatif Kualitatif dan $R \& D$. Bandung: Alfabeta.

7. Tabikh, Mohamad. 2014. Downtime Cost and Reduction Analysis: Survey Result. Sweden: Malardalen University. 